\title{
A tale of 2 treatments: The best of times or the worst of times?
}

\author{
Jack H. Boyd, MD
}

\author{
From the Department of Cardiothoracic Surgery, Stanford University School of Medicine, Stanford, Calif. \\ Disclosures: Author has nothing to disclose with regard to commercial support. \\ Received for publication March 14, 2016; accepted for publication March 14, 2016; available ahead of print April \\ 26, 2016. \\ Address for reprints: Jack H. Boyd, MD, Department of Cardiothoracic Surgery, Stanford University School of \\ Medicine, Falk Building CV-229, 300 Pasteur Dr, Stanford, CA 94305 (E-mail: jackboyd@ stanford.edu). \\ J Thorac Cardiovasc Surg 2016;152:137-8 \\ $0022-5223 / \$ 36.00$ \\ Copyright (c) 2016 by The American Association for Thoracic Surgery \\ http://dx.doi.org/10.1016/j.jtcvs.2016.03.039
}

Coronary artery bypass grafting (CABG) is the most common type of cardiac surgery. ${ }^{1}$ The left internal mammary artery (LIMA)-to-left anterior descending (LAD) anastomosis is nearly the sine qua non of CABG. Numerous studies have shown better long-term patency rates and survival in patients undergoing $\mathrm{CABG}$ with the LIMA-to-LAD anastomosis, ${ }^{2}$ and the use of this anastomosis has become a marker of quality control for CABG. Consequently, any factor that compromises the integrity of this graft merits attention.

Stenosis of the proximal left subclavian artery (LSCA) is a scenario in which the viability of the LIMA-to-LAD anastomosis is threatened. LSCA introduces the possibility of coronary-subclavian steal syndrome (CSSS) and jeopardizes the long-term benefit of the LIMA graft.

In their article in this issue of the Journal, Hong and colleagues $^{3}$ address a real obstacle to surgical myocardial revascularization. The incidence of proximal LSCA stenosis ranges between $1 \%$ and $2 \%$, and approximately 400,000 CABG operations are performed annually. ${ }^{4}$ This indicates that as many as 8000 patients could be affected each year. Recognition of the clinical issue and exploration of this issue have an immediate and tangible impact on the daily practice of cardiac surgery. The authors ask us to actively consider our own evaluations for LSCA stenosis and the most effective method for treating it.

The transition of treatment of LSCA stenosis from primarily surgical to percutaneous and the evolution from staged treatment to hybrid treatment of patients with LSCA stenosis and coronary artery disease reflect changes in practice in the field as a whole. As improved medical management and technological advancements have permitted alternative, frequently less invasive methods for the treatment of coronary artery disease, surgeons must continue to ensure that each individual $\mathrm{CABG}$ procedure minimizes risk and maximizes benefit. Incorporating hybrid procedures into practice requires access to the appropriate equipment, adoption of new or adjusted skill sets, collaboration, and proper testing and validation of the new methods.

This study took a straightforward approach and was able to glean real data to support the change from an adaptation in

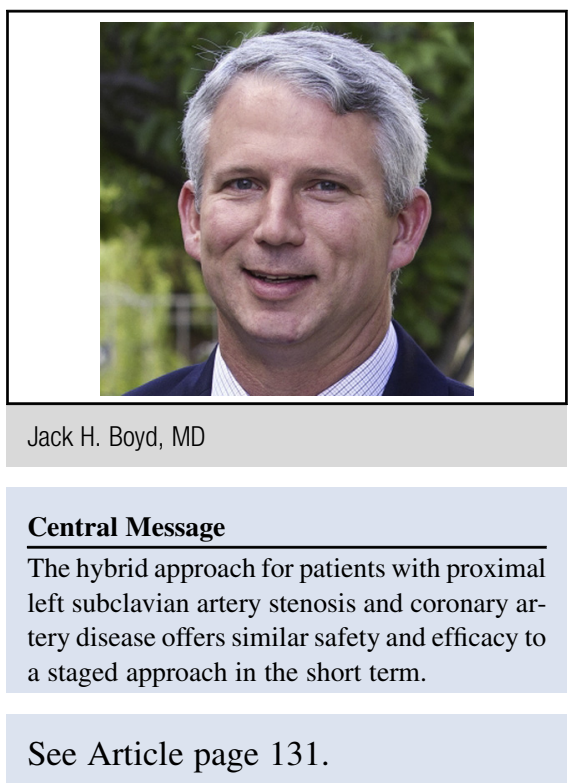

practice. Large, blinded, randomized control trials, although preferable in many instances, are often not practical. The authors took a measured and thoughtful approach to evolution in clinical practice. They examined the patient population referred for CABG with significant LSCA stenosis. They identified significant LSCA stenosis in $1.8 \%$ of their patients (20 of 1132) from the hybrid treatment era (2013-2015) and in $1.5 \%$ (23 of 1533) from the staged treatment era (2008-2012) who underwent LSCA angiography (between $30 \%$ and $40 \%$ of their CABG population) immediately after cardiac catheterization. They compared these patients retrospectively, or maybe more appropriately, introspectively. In the hybrid treatment cohort, patients with proximal LSCA stenosis and coronary artery disease underwent percutaneous intervention with stent placement to the LSCA and CABG during a single operation in a hybrid operating suite. In contrast, the staged treatment cohort underwent percutaneous intervention with stenting, followed by CABG 4 weeks later. The break in periods corresponded to the availability of a hybrid operating suite in the authors' institution. Demographic data, preoperative risk factors, intraoperative measures, and postoperative outcomes were analyzed.

We frequently hear that "the sky is falling" for surgical myocardial revascularization; it is the worst of times for cardiac surgery. Case volumes are down, and scrutiny is up. Maximizing the likelihood of success for the LIMA-to-LAD anastomosis, and measuring and analyzing the novel and innovative techniques needed to do so, in a manner that appeals to both patients and referring 
physicians, paves the way toward achieving the appropriate use of CABG. This would certainly be the best of times.

\section{References}

1. National Heart, Lung, and Blood Institute. Types of heart surgery. Available at: https://www.nhlbi.nih.gov/health/health-topics/topics/hs/types. Accessed April $20,2016$.
2. Karthik S, Fabri BM. Left internal mammary artery usage in coronary artery bypass grafting: a measure of quality control. Ann R Coll Surg Engl. 2006;88: 367-9.

3. Hong H, Wu L, Yang C, Dong NG. Results of a hybrid procedure for patients with proximal left subclavian artery stenosis and coronary artery disease. J Thorac Cardiovasc Surg. 2016;152:131-6.

4. National Center for Health Statistics. Inpatient surgery. Available at: http://www. cdc.gov/nchs/fastats/inpatient-surgery.htm. Accessed March 13, 2016. 